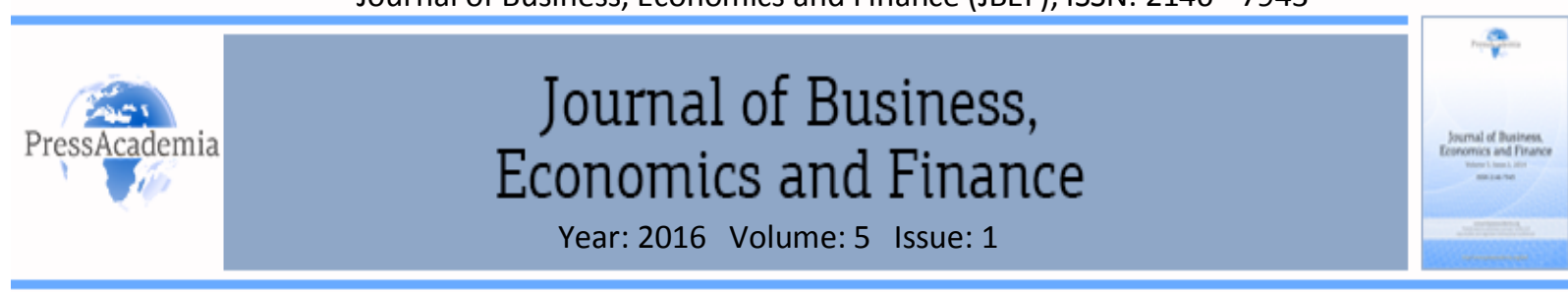

\title{
THE RELATIONSHIP BETWEEN INCOME INEQUALITY AND TERTIARY ATTAINMENT FOR DEVELOPING COUNTRIES: IS IT A U-SHAPED RELATIONSHIP?
}

\section{DOI: 10.17261/Pressacademia.2016116553}

\section{Ozlem Yorulmaz}

Istanbul University.yorulmaz@istanbul.edu.tr

\begin{abstract}
This study explores the effects of tertiary attainment and per capita income on income inequality for 30 developing countries over the period 1990-2008 by three different estimation approaches namely classical estimation of a fixed effects panel data model, quantile panel type regression, and robust panel type regression models. The findings reveal that there is no evidence of the Kuznets hypothesis of inverted $\mathrm{U}$ curve dependence of income inequality on income. However, the results of robust panel type regression and quantile regression for the $20^{\text {th }}$ percentile indicate this relationship as U-shaped. According to robust panel type regression, the effect of tertiary attainment on income inequality is significant and U-shaped, as well.
\end{abstract}

Keywords : Income inequality, Kuznets inverted U hypothesis, Quantile regression, Robust regression, tertiary education. JEL Classification : C14, C23, 132

\section{INTRODUCTION}

As the gap between the rich and poor continues to widen steadily in line with economic development, income inequality has been a prevalent concern for both advanced and developing countries since it brings about undesirable outcomes in economic, social and political areas such as poor public health, high crime ratios, political instability, lower average education levels. "High and sustained levels of inequality, especially inequality of opportunity can entail large social costs. Entrenched inequality of outcomes can significantly undermine individuals' educational and occupational choices" (Dabla-Norris et al.,2015). The increase in income inequality among families and neighbourhoods has implications for the average years of schooling particularly for lower income families (Campbell et al., 2005).

Additional to an outcome role of education as mentioned above, educational attainment has been considered as one of the most crucial determiner of income inequality (De Gregorio and Wha-Lee, 2002). Education brings about such an expectancy of people better off as making contribution to their work and daily life; better jobs, better social status, easy access to information, easily overcoming with environmental and technological changes. According to Knigth and Sabot (1983), the impacts of education can be explained under two main topics namely, "composition effect" and "compression effect". The composition effect states that the increase in the proportion of educated labour initially increases the income inequality; this approach is similar to the process of Kuznets Hypothesis. Kuznets (1955) explained that as countries developed, income inequality initially rose, subsequently peaked, and then declined during the later phases of economic development by using both time series and cross-sectional data. Over the course of time, this hypothesis has been referred to as the 'inverted-U hypothesis'. From the educational perspective the emphasis of Kuznets' approach can be interpreted as following: In the lowest income groups, mostly people have very low level of education and their income is more equally distributed. As the level of education improves in line with the economic development, income increases and urbanization rises, and the distribution of income becomes more unequal before reaching the peak. As the average level of education attains to higher levels in a society and economy becomes 
further matures, income distribution attains more equal level. With respect to "compression effect", it leads to decreasing effect of education on income inequality. This process arises from the competition in the labour market.

This paper explores the effect of tertiary attainment on income inequality for developing countries between the period of 1990-2008 by three different estimation approaches namely classical estimation of a fixed effects panel data model, quantile panel type regression, and robust panel type regression models. Our dataset reflects economic, social, political and demographic diversities of countries. It is likely to encounter some countries which are away from the remaining in the dataset. To the best of our knowledge the diagnosis of outlying observations in panel data has not been studied yet. Statistical analysis and interpretations based on a dataset including outlying observations or not may differ significantly. To cope with this shortcoming robust statistics are preferred in the literature. Unlike the classical estimation of the panel data model, quantile regression reflects differences in the response of the dependent variable to changes in the regressors at various points along the conditional distribution of the dependent variable (McGregor et al. 2015), and robust regression provides a resistant estimated coefficient vector against outlying observations both on the dependent and independent variables. By employing different perspectives on the estimation of our model, we provide estimates that are not sensitive to outliers, take into consideration different percentiles of income inequality, and hence obtain a complete view of the effects of income and education on income inequality.

This study makes several contributions to the existing literature. To the best of our knowledge, this is the first paper that considers both quantile regression and robust regression approaches for the investigation of the relationship between income inequality and tertiary attainment. While examining the stationarity of variables, we take into consideration the possibility of the dependency of panels and small time dimension problem cases, and therefore employed panel bootstrap block unit root tests.

The paper is organised into five sections. Section 2 reviews the relevant literature for the effect of education on income. The methodology is explained in Section 3. Section 4 present data and the empirical results and, finally, Section 5 concludes.

\section{LITERATURE REVIEW}

Our investigation is based on the process postulated by Kuznets which is mentioned in the study of Knight and Sabot (1983). The validity of Kuznets hypothesis has been widely studied in the literature however, the relationship between income per capita and income inequality remains unclear due to the different datasets, different estimation techniques. In the study of Bulir and Gulde (1995), it was found that the inverted-U hypothesis accounts for only a limited part of the inter-country variation of the income distribution. Dimelis and Livada (1999), reported that economic growth has a reducing effect on income inequality in the US and UK, but has an increasing effect on inequality in Greece. In the studies of Ravallion and Chen (1997), Easterly (1999), and Dollar and Kraay (2002), a significant relationship between economic growth and high levels of income inequality were not found. Gallup (2012) included a large number of countries in his study and obtained that there is no evidence of inverted- $U$ hypothesis; however, inequality declines in low-income countries, whereas it increases in high-income countries, and a U-shaped pattern shows up in a non-parametric trend.

Education is an essential opportunity for low income class to improve their skills and it is frequently addressed in the studies of economic development as a factor that reduces urban inequality and increases economic growth. However recent studies reveal that the relationship between income inequality and educational attainment are controversial. The study of Knight and Sabot (1983) as mentioned in the previous section, explains that the link between "compression" and "composition" effects determines the income inequality. Barro (2000) examined the relation between income inequality and educational attainment; it was concluded that there is a positive relationship between income inequality and higher education attainment, whereas there is a negative relationship for primary education attainment. In the study of Checchi (2001), U shaped relationship between educational attainment and income inequality was found. Degregoria and Wha Lee (2002) investigated the mentioned relationship over a broad range of countries by Seemingly Unrelated Regressions (SUR) model and obtained a negative relationship between income inequality and median 
educational attainment. They emphasised that higher education attainment plays a significant role in making income distribution more equal. Carnoy, Loyalka and Androuschak (2014), examined the relationship between higher education expansion and income inequality using a standard human capital model for BRIC countries. Their study obtained that higher education expansion contributes to greater income inequality in China, as to other BRIC countries the effect of higher education as negligible. According to Schultz (1963), increase of educational attainment effects both lower and higher incoming groups, as higher incoming group will earn less due to the competition and the lowest incoming group will have more income. The findings of Abdullah et al, (2011) are in line with Schultz (1963), they employed a Meta regression analysis including 64 empirical studies and obtained that education have reducing effect on rich and increasing effect on the poor thus the gap between lower and higher incoming groups becomes narrower.

Checchi and Van de Verfhorst (2014) emphasized that the educational reforms have an effect on the distribution of the quality and quantity of education. Moreover, educational policies have an impact on the income distribution.

The relationship between income inequality and education has been dealt recently by the studies of Kraugman $(2015)^{1}$. He emphasized that education is not a cure for income inequality since increasing education is not able to bring down wages of the top and the improved conditions of low and middle income will not change the existence of the very wealthiest. The study of Herishbein, Kearney and Summers (2015) is in line with the approach of Krugman (2015). They asserted that increasing educational attainment does not significantly change overall income inequality since a large share of income inequality is at the top of the income distribution and college shares will not shrink those differences. However, it is also mentioned in their study that increasing educational attainment reduce inequality in the bottom half of the income distribution, by pulling up the income of those near the $25^{\text {th }}$ percentile.

\section{METHODOLOGY}

The affective components of tertiary attainment as the government policies, rates of public subsidies for lower incoming students, tuition fees for universities or institutes show difference across countries. Some of these differences may cause outlying observations. Considering the different patterns in the set of developing countries, panel regression and robust regression approaches were employed in our empirical models in addition to classical estimation of the fixed effects panel data model. The quantile regression method was developed by Koenker and Bassett (1978); it allows for the effects of the independent variable to vary over the quantiles.

Different from the ordinary least squares, quantile regression is based on the conditional quantile functions of the dependent variable where each function presents the behaviour of a specific point on the conditional distribution. Furthermore, the quantile regression approach is resistant to outlying observations in the $y$ direction (Verardi and Croux, 2009; McGregor et al., 2015) and convenient in the case of asymmetric or fattailed conditional distributions. Koenker (2004) adapted the quantile regression approach for the estimation of fixed effects panel data.

A conditional quantile model can be modelled as follows:

$Q_{\tau}\left(y_{i} \mid x_{i}\right)=\alpha(\tau)+x_{i} \beta(\tau) \quad j=1, \ldots, m_{i}, \quad i=1, \ldots, n$

where $\tau(\tau \in[0,1])$ corresponds to quantiles, $\alpha_{i}$ is a vector of unobserved fixed effects, $i$ is the index for countries, $j$ is the number of observations per country $m_{j}, x$ is the matrix of explanatory variables, and $y$ is the dependent variable. Koenker (2004) proposed to obtain parameter estimates by solving the following objective function:

\footnotetext{
${ }^{1}$ Nobel laureate economist
} 
$\min _{(\alpha, \beta)} \sum_{k=1}^{q} \sum_{j=1}^{n} \sum_{i=1}^{m_{i}} \omega_{k} \rho_{\tau k}\left(y_{i j}-\alpha_{i}-x_{i j}^{T} \beta\left(\tau_{k}\right)\right)+\lambda \sum_{i=1}^{n}\left|\alpha_{i}\right|$

where $\mathrm{q}$ is the index for quantiles, $\omega_{k}$ is a weight function, and $\rho_{\tau k}$ corresponds to the quantile loss function. $\left(\rho_{\tau k}(u)=u\left(\tau_{k}-I(u \leq 0)\right)\right)$ and the last part of the expression is called the penalty term. $\lambda$ is a tuning parameter that defines the magnitude of the penalty term and serves to reduce the additional variability based on the estimation of the individual fixed effects (Koenker, 2004; Lamarche, 2010). The penalty term provides a solution for the computational problem of estimating a large number of parameters. According to the definition of Lamarche (2011), it is possible to view $\lambda$ as controlling the vertical distance between the empirical conditional density function of the $\mathrm{i}^{\text {th }}$ country and the one of the pooled sample.

The relationship of tertiary attainment across the conditional income inequality distribution was denoted considering the $10^{\text {th }}, 20^{\text {th }}, 50^{\text {th }}, 70^{\text {th }}$, and $90^{\text {th }}$ percentiles in this study. Estimations of the standard errors are obtained by the bootstrap procedure (Bose and Chartterjee, 2003). ${ }^{2}$

The robust regression approach is the other estimation technique we included in the study. Quantile regression is not resistant against outliers in the space of explanatory variables; as mentioned previously, it is resistant only against outlying observations in the y dimension. Bramati and Croux (2007) proposed two robust approaches to fixed effects panel data models, namely within-groups generalised $M$ estimator and withingroups MS estimator, which are resistant against outliers in the $y$-direction and against bad leverage points (outlying observations in the $x$-direction and can tilt the regression line). Both approaches are based on two main steps, namely centering series with respect to median and adapting a robust estimator to standard withingroups estimator process. Verardi and Wagner (2012) studied the aforementioned robust approaches and proposed an $\mathrm{S}$ estimator through the estimation process.

We consider the fixed effects linear panel data model

$y_{i t}=\alpha_{i}+x_{i t}^{t} \beta+\varepsilon_{i t}$

where subscript $i$ denotes the cross-section dimension and $t$ denotes time series dimension. $Y_{i t}$ indicates dependent variables, $\mathrm{x}_{\mathrm{it}}$ is the $\mathrm{Kx} 1$ column vector of explanatory variables $\beta$ is the $\mathrm{K} \times 1$ column vector of regression parameters, and $\alpha_{i}$ values are the time-invariant fixed effects.

The steps of the method that Verardi and Wagner (2012) proposed can be summarised as follows:

-Centre all variables by removing the median:

$\tilde{y}_{i t}=y_{i t}-\operatorname{med}_{i} y_{i t}$

$\tilde{x}_{i t}^{(j)}=x_{i t}^{(j)}-\operatorname{med}_{i} x_{i t}^{(j)}$

We run an $\mathrm{S}$ estimator of the centred dependent variable, $\tilde{y}_{i t}$, on the centred explanatory ones, $\tilde{x}_{i t}^{(j)}$, and obtain the estimated parameters

$\tilde{\beta}=\underset{\beta}{\arg \min } \sigma\left(r_{1}(\beta), \ldots r_{N T}(\beta)\right)$ where $r$ are the estimated residuals and $\sigma$ is an M estimator of scale. $\beta$

-Using the residuals from the previous step, an identification of outliers is performed (standardised residuals larger than 1.96).

-Observations are weighed and standard fixed effects estimator is estimated. ${ }^{3}$

\footnotetext{
${ }^{2}$ rqpd package in R written by Roger Koenker and Stefan Holst Bache was used.

${ }^{3}$ Stata codes of the robust estimator was provided by Vincenzo Verardi
} 


\section{DATA, DESCRIPTIVE STATISTICS, AND FINDINGS}

In this study, income inequality was evaluated by Theil indices that are estimated by the University of Texas Inequality Project (UTIP-UNIDO). The Theil index is based on the following calculation:

$T=\frac{1}{n} \sum_{i=1}^{n} \frac{y_{i}}{\mu} \ln \left(\frac{y_{i}}{\mu}\right)$

where $i$ corresponds to index group, $y_{i}$ refers to average wage in each index group, and $\mu$ is the average wage of the entire population; in the case of perfect equality, it equals 0.

Before evaluating the effect of tertiary attainment on income inequality, we investigated the existence of Kuznets' inverted $U$ pattern on our dataset. The following empirical equations were modelled in this study:

$$
\begin{aligned}
& \text { LTheil }_{i t}=\beta_{0}+\beta_{1} L G D P_{i t}+\beta_{2} L G D P_{i t}^{2}+u_{i}+e_{i t} \\
& \text { LTheil }_{i t}=\beta_{0}+\beta_{1} L_{E d u c_{i t}}+\beta_{2} L E d u c_{i t}^{2}+u_{i}+e_{i t}
\end{aligned}
$$

where the subscripts $i$ and $t$ indicate countries and years, respectively. Dependent variables refer to the logarithm of Theil indices (LTheil), $u_{i}$ is the country-specific fixed effects, and $e_{i t}$ is the traditional error term. Explanatory variables in models were arranged as follows: GDP per capita constant prices based on purchasing power parity (LGDP), tertiary attainment as a percentage of the total population ${ }^{4}$ (LEduc). Explanatory variables described above are in logarithm form. The data consist of 30 developing countries ${ }^{5}$ between the years of 1990 to 2008, and the World Bank Database (World Bank Development Indicators-WDI) is the main source in this study. Both empirical models were considered with three different estimation approaches of panel data models, namely classical estimation, quantile regression, and robust estimation.

Prior to the estimation of empirical models, the stationarity of variables was investigated to avoid spurious findings. Jacobsen and Giles (2006) pointed out that most of the studies that investigate the inverted-U pattern (particularly environmental Kuznets curves) do not pay attention to the importance of non-stationary data. Wagner (2008) emphasised the previously-ignored nonstationary investigation in addition to several disregarded issues through the econometric approaches of testing the existence of the environmental Kuznets curve in the literature. The disregarded points can be summarised as:

-not investigating stationarity of nonlinear transformations of variables

-relying upon the cross-sectional independence assumption and using first-generation unit root tests. He pointed out that the assumption of the independence of panels is implausible and that first-generation methods perform poorly for small samples. Therefore, he implemented a second-generation unit root test through bootstrap approaches for a small sample size in his study.

Following the study of Wagner (2006), panel unit tests based on bootstrap methods, namely Robust Block Bootstrap (RBB) and Modified Wild Bootstrap (MWB) were choosen here alongside Im-Peseran-Shin (IPS), Fisher-ADF, and Fisher-PP tests to investigate the stationarity of variables. IPS, Fisher-ADF, and Fisher-PP tests are named as first-generation tests that assume the independence of panels, whereas the other two tests consider the dependency of cross-sectional panels. The RBB test was developed by Palm, Smeekes, and Urbain (2011), and their approach is an extension to the panels of the unit root test of Paparoditis and Politis (2003). Smeekes and Urbain (2014) proposed the MWB test that takes dependence within and different elements of the time series into account.

Considering three variables, GDP per capita, tertiary attainment and Theil index, some descriptive statistics are presented in Appendix 1. Some countries seem different from the overall, for instance Oman is the most striking one with the highest GDP per capita and the lowest proportion of tertiary attainment rate. Russia,

\footnotetext{
${ }^{4}$ Lagged by 5 years

${ }^{5}$ Due to unavailability of the Theil indices and ratios of tertiary attainment for some countries, our analysis does not include all developing countries.
} 
Romania, Poland and Ukraine seem to have similar pattern, however different from the remaining, they have very high tertiary attainment ratios and low Theil indices.

Table 1 reveals the results of the unit root tests. The null hypothesis is that each panel contains a unit root. As can be seen from Table 1, considering the findings of the five unit root tests, all variables are I(1) except LTheil. Since LTheil is $I(0)$, we do not investigate the existence of cointegration in the empirical models. Our analysis goes on to evaluate the empirical models considering stationary series.

Investigation of the inverted-U pattern was done with the first empirical model (eq.5) and the results are exhibited in Table 2. Table 2 reports panel regression results by using classical estimation of fixed effects ${ }^{6}$ (column 1), quantile regression (columns 2-5), and robust regression (column 6). The results based on the quantile regression for $20^{\text {th }}$ percentile and robust regression confirm $U$-shaped relationship.

Table 3 exhibits the findings of the second empirical model (Eq. 6). Considering the results of classical estimation of fixed effects and quantile regression, tertiary attainment has no impact on income inequality for developing countries. However, robust regression obtained significant effect of tertiary attainment on income inequality, the relationship between tertiary attainment and income inequality is U-shaped. Although the results of quantile regression are not statistically significant, the pattern between income inequality and tertiary attainment is striking. For the lower and middle percentiles it is inverted- $U$ shape whereas it is $U$ shaped for the higher percentiles.

Overall, the findings indicate that there is no evidence of Kuznets' inverted- $U$ curve type relationship between GDP per capita and income inequality for the studied developing countries. However, results of robust regression and quantile regression for the $20^{\text {th }}$ percentile indicate that the aforementioned relationship between GDP per capita and income inequality is U-shaped. As mentioned in Section 2, recent studies reveal that the relationship between income inequality and income remains controversial. According to Oyvat (2010), social structures of developing countries might show a negative or slightly positive shape for the first phase. Gallup (2012) emphasised the existing relationship between income and income inequality as being U-shaped. These results are compatible with our findings. With respect to tertiary attainment, only findings of robust regression confirm that education and education square are significant; the relationship is a U-shaped. This result is in line with the study of Checci (2001) that obtained the pattern of relationship between income inequality and average years of schooling as U-shaped.

\footnotetext{
${ }^{6}$ A Hausman test was performed to determine whether a random or fixed effect is more appropriate, and it was indicated that the fixed effect (FE) model is preferable. Additionally, the appropriateness of FE model against pooled OLS was investigated by an F test for each empirical model, and it is inferred to use the FE model.
} 
Table 1: Unit Root Tests

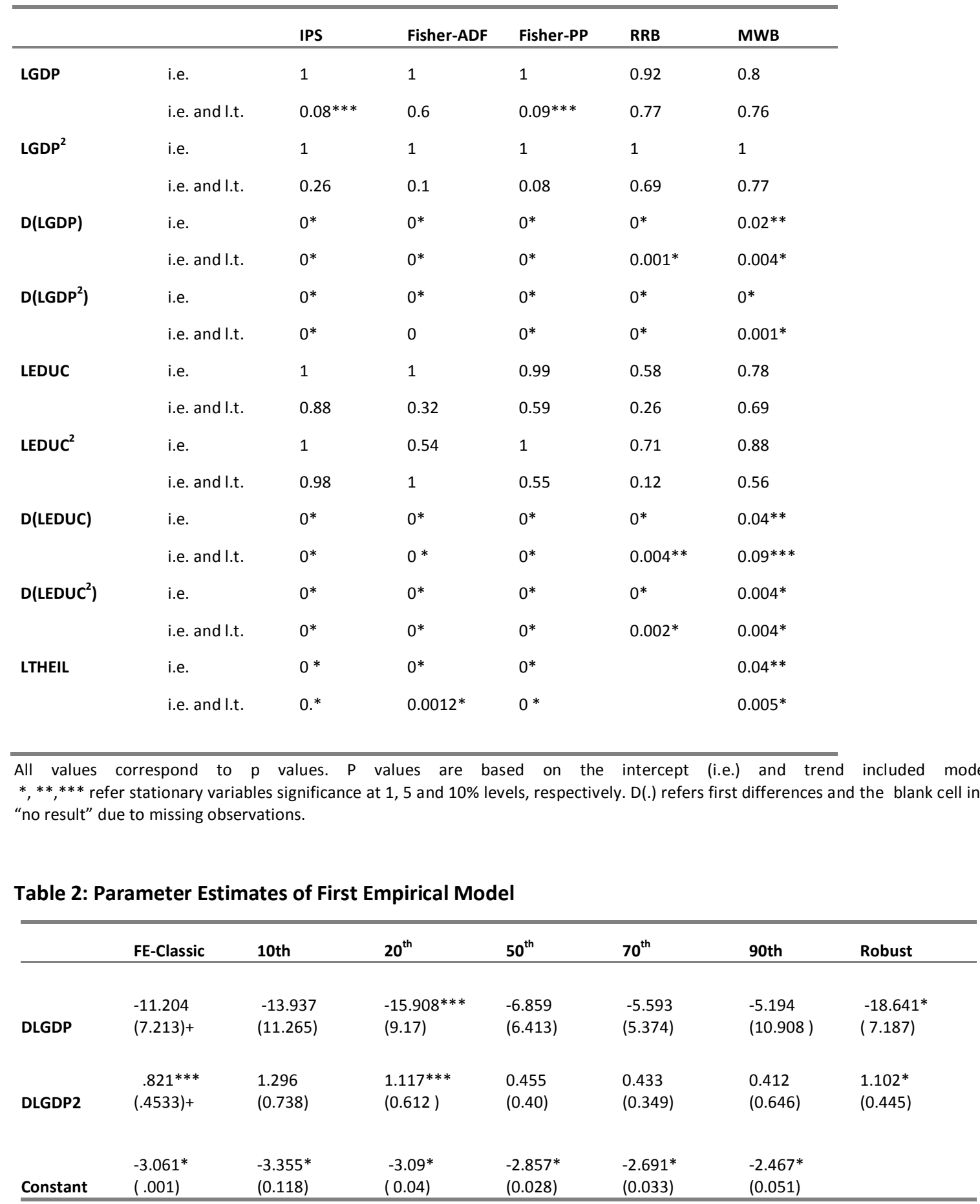

(.) Parenthesis indicate the standard errors . ' + ' refers robust standard errors.

$*, * *, * * *$ represent significance at 1,5 and $10 \%$ levels, respectively. 
Table 3: Parameter Estimates of Second Empirical Model

\begin{tabular}{|c|c|c|c|c|c|c|c|}
\hline & FE-Classic & 10th & 20th & $50^{\text {th }}$ & $70^{\text {th }}$ & $90^{\text {th }}$ & Robust \\
\hline DLEDUC2 & $\begin{array}{c}-.0125 \\
(0.046)+\end{array}$ & $\begin{array}{l}-0.05 \\
(0.138)\end{array}$ & $\begin{array}{l}-0.02 \\
(0.05)\end{array}$ & $\begin{array}{l}0.016 \\
(0.041)\end{array}$ & $\begin{array}{l}0.0514 \\
(0.061)\end{array}$ & $\begin{array}{l}0.0262 \\
(0.163)\end{array}$ & $\begin{array}{l}.654 * * \\
(0.291)\end{array}$ \\
\hline Constant & $\begin{array}{l}-3.152^{*} \\
(0.006)\end{array}$ & $\begin{array}{l}-3.484^{*} \\
(0.115)\end{array}$ & $\begin{array}{l}-3.136^{*} \\
(0.06)\end{array}$ & $\begin{array}{l}-2.888^{*} \\
(0.03)\end{array}$ & $\begin{array}{c}-2.706^{*} \\
(0.035)\end{array}$ & $\begin{array}{l}-2.529 * \\
(0.051)\end{array}$ & \\
\hline
\end{tabular}

(.) Parenthesis indicate the standard errors . ' + ' refers robust standard errors.

$*, * *, * * *$ represent significance at 1,5 and $10 \%$ levels, respectively.

\section{CONCLUSION}

This paper investigates the effect of tertiary attainment on income inequality for 30 developing countries from 1990 to 2008 by employing three different empirical models. Since the sample reflects the economic, financial, political and demographic diversities of countries, we considered panel quantile regression and panel robust regression approaches in addition to the classical estimation of fixed effects panel data model to refrain the potential effects of outlying observations.

We began our analysis to explore the existence of Kuznets' inverted- $U$ and afterwards evaluated the effect of tertiary attainment on income inequality. Both subjects have been widely discussed in the literature however the empirical findings are not consistent due to different estimation techniques, inclusion of nonstationary regressors, and selection of different country groups and variables. Taking into account the small time dimension of the data and the possible dependency of panels, stationarity of variables were tested with bootstrap-based panel unit roots, namely MWB and RBB, alongside first-generation unit root tests.

Our findings confirm that there is no evidence of Kuznets' inverted U-shaped relationship between income and income inequality for developing countries. However, the quantile regression for the $20^{\text {th }}$ percentile and robust regression approach conclude a U-shaped relationship between income and income inequality, and this finding is consistent with the study of Gallup (2012). The examination of the effect of tertiary attainment is based on the process postulated by Kuznets which is mentioned in the study of Knight and Sabot (1983). However, the result of robust regression is contrary to Knight and Sabot (1983), it is obtained that the relationship between tertiary education and income inequality is as U-shaped. This finding is in line with the study of Checci (2001).

\section{REFERENCES}

Barro, R. J. 2000, “Inequality and Growth in a Panel of Countries”, Journal of Economic Growth, 5(1), pp. 5-32.

Bose, A., \&Chatterjee, S. 2003, “Generalized bootstrap for estimators of minimizers of convex functions",J. Stat. Planning and Inf., 117, pp. 225-239.

Bramati, M.C., \& Croux, C. 2007, “Robust Estimators for the Fixed Effects Panel Data Model”, Econometrics Journal, 10(3), pp. 521-540

Bulir, A., \& Gulde, A.M. 1995, “Inflation and income distribution: Further evidence on empirical links", IMF Working Paper 95/86. http://papers.ssrn.com/sol3/papers.cfm?abstract_id=883233. Accessed 10 July 2015.

Campbell, M.,Haveman, R., Sandefur, \& G.-Wolfe, B. 2005, "Economic inequality and educational attainment across ageneration". http://www.irp.wisc.edu/publications/focus/pdfs/foc233b.pdf. Accessed 10 July 2015.

Carnoy, M., Loyalka, P., Androuschak, G., \& Froumin, I. 2014, “The Concept of Public Goods, the State, and Higher Education Finance: A View from the BRICS", Higher Education, 68(3), pp. 1-20.

Checci,D. 2001, “Education, inequality and income inequality. LSE Research paper”, http://eprints.Ise.ac.uk/6566/. Accessed 15 May 2015. 
Checchi, D., \&Van De Werfhorst, H. 2014, "Educational Policies and Income Inequality", IZA Discussion Paper DP No.8222. http://ftp.iza.org/dp8222.pdf. Accessed 17 May 2015.

Dabla-Norris, E.,Kochhar, K., Suphaphiphat, N., Ricka, \& Tsounta, E. 2015, “Causes and consequences of income inequality: A global perspective", IMF staff discussion note. https://www.imf.org/external/pubs/ft/sdn/2015/sdn1513.pdf. Accessed 3 July 2015.

De Gregorio, J., \& Lee. J.W. 2002, "Education and Income Inequality: New Evidence from Cross-Country Data", Review of Income and Wealth, 48(3), pp. 395-416.

Dimelis, S., \& Livada, A. 1999, "Inequality and Business Cycles in the US and European Countries", International Advances in Economic Research, 5(3), pp.321-338.

Dollar, D., \& Kraay, A. 2002, “Growth is Good for the Poor”, Journal of Economic Growth, 7(3), pp. 195-225.

Easterly, W. 1999, “Life during Growth: International Evidence on Quality of Life and per capita Income”, Journal of Economic Growth 4, pp. 239-276.

Gallup, J.L. 2012, "Is there a Kuznets curve?", Working paper.

https://www.pdx.edu/econ/sites/www.pdx.edu.econ/files/kuznets_complete.pdf. Accessed 10 May 2015.

Hershbein, B., Kearney, M., \& Summers, H. 2015, "Increasing education: What it will and will not do for earnings and earnings inequality", http://www.brookings.edu/blogs/up-front/posts/2015/03/31-what-increasing-education-will-and-wont-do-for-earnings-inequalityhershbein-kearney-summers. Accessed 20 October 2015.

Jacobsen, P. E., \& Giles, D. E. A. 2006, “Income Distribution in the United States: Kuznets' Inverted U-Hypothesis and Data NonStationarity", The Journal of International Trade and Economic Development, 7, pp. 405-423

Knight, J., \& Sabot, R. 1983, “Educational expansion and the Kuznets effect”, The American Economic Review, 73(5), pp. 1132-36.

Koenker, R., \& Bassett, S. 1978, “Regression Quantiles”, Econometrica, 46, pp. 33-50.

Koenker, R. 2004, “Quantile Regression for Longitudinal Data”, Journal of Multivariate Analysis, 91 (1), pp.74-89.

Kraugman, P. 2015, “Knowledge Isn't Power", http://www.nytimes.com/2015/02/23/opinion/paul-krugman-knowledge-isntpower.html?_r=0. Accessed 15 October 2015.

Kuznets, S. 1955, "Economic Growth and Income Inequality”, American Economic Review, 45(1), pp. 1-28.

Lamarche, C. 2010, “Robust penalized quantile regression estimation for panel data”, Journal of Econometrics 157(2), pp. 396-408.

McGregor, N., Isaksson, A., \& Kaulich, F. 2015, "Importing, exporting and the productivity of services firms in Sub Saharan Africa". The journal of International Trade \& Economic Development, 24, pp. 499-522.

Palm, F.C., Smeekes, S., \& Urbain, J.P. 2011, “Cross-sectional dependence robust block bootstrap panel unit root tests", Journal of Econometrics, 163(1), pp. 85-104.

Paparoditis, E., \& Politis, D.N. 2003, “Residual-based block bootstrap for unit root testing”. Econometrica, 71, pp. 813-856

Ravallion, M., \& Chen, S. 1997, "What can new survey data tell us about recent changes in distribution and poverty?", World Bank Economic Review, 11(2), pp. 357-382.

Schultz, T. W. 1963, The Economic Value of Education. New York: Columbia University Press.

Smeekes, S., \& Urbain, J.P. 2014, “On the Applicability of the Sieve Bootstrap in Time Series Panels", Oxford Bulletin of Economics and Statistics, 76(1), pp. 139-151.

Oyvat, C. 2010, "How Urbanization Affects the Inequality in Developing Countries: A Critique of Kuznets Curve”, University of Massachusetts New School University Economics Graduate Student Workshop 23-24 October, 2010.http://scholar.google.com/citations?view_op=view_citation\&hl=en\&user=ku4HdlwAAAAJ\&citation_for_view=ku4HdlwAAAAJ:ux6o8ySG0sC. Accessed 15 April 2015.

University of Texas, Inequality Project, http://utip.gov.utexas.edu/data.html, Accessed 15 Nov 2015.

Verardi, V., \& Wagner, J. 2012, "Productivity Premia for German Manufacturing Firms Exporting to the Euro-Area and Beyond: First Evidence from Robust Fixed Effects Estimations", The World Economy, Wiley Blackwell, 35(6), pp. 694-712.

Verardi, V., \& Croux, C. 2009, “Robust Regression in Stata”, Stata Journal, 9 (3), pp. 439-453.

Wagner, M. 2008, “The carbon Kuznets curve: A cloudy Picture emitted by bad econometrics?", Resource and Energy Economics, 30(3), pp. 388-408.

World Bank: World Development Indicators.

http://databank.worldbank.org/data/views/variableselection/selectvariables.aspx?source=World-Development-Indicators (2015). Accessed 15 Nov 2015 